\title{
A Study on Microbial Characteristics of Food Products Developed from Dates (Phoenix dactylifera L.)
}

\author{
Nikita Wadhawan* and Rythm Bansal \\ DFT, CDFST, MPUAT, Udaipur313001, Rajasthan, India \\ *Corresponding author
}

\begin{tabular}{|l|}
\hline Key w o r d s \\
Phoenix dactylifera, \\
$\begin{array}{l}\text { Dates, Organoleptic } \\
\text { characteristics, } \\
\text { Shelf life }\end{array}$ \\
\hline Article Info \\
\hline $\begin{array}{l}\text { Accepted: } \\
\text { 06 July 2018 } \\
\text { Available Online: } \\
\text { 10 August } 2018\end{array}$ \\
\hline
\end{tabular}

\section{A B S T R A C T}

Phoenix dactylifera L., commonly known as the date palm is a primeval plant and has been cultivated for its edible fruit in the desert oasis of the Arab world for centuries. This fruit is a rich source of carbohydrates, dietary fibers, certain essential vitamins and minerals. In addition to its dietary use the dates are of medicinal use and are used to treat a variety of ailments in the various traditional systems of medicine. The study was planned with the objectives to develop and assess the shelf life of value added products of dried dates. The dates products that is ready to cook (instant cake premix) and ready to eat (dates churan, dates cookies, and dates chakli) were developed and subjected to sensory evaluation. The shelf life of the standardized products was assessed based on sensory qualities (appearance, colour, taste, flavour, texture and overall acceptability) using nine point Hedonic scale, moisture content and microbial growth (yeast and mould count) for the period of 3 months. The results revealed that there was no significant difference was found in sensory characteristics and microbial load (yeast and mould count) in developed dates products (dates churan, dates cookies and instant cake premix) during storage period indicating that they were safe for consumption up to 3 months but in dates chakli there were significant changes in the overall acceptability $(6.93 \pm 1.36)$ after 3 months and significant microbial changes $(0.54 \pm 0.13)$ were also seen signifying that it was not safe for consumption at the 3 month of storage. Significant increase in the moisture content of dates products at second $(1.05 \pm 0.06,1.33 \pm 0.05,2.15 \pm 0.13$ and $2.15 \pm 0.02)$ and third $(2.05 \pm 0.05,2.56 \pm 0.02,4.12 \pm 0.09$ and $4.43 \pm 0.04)$ month of storage period was also seen. Hence it can be said that the developed products of dates except chakli were safe for consumption even after three months of storage stating that they have a long shelf life. The alterations in sensory characteristics of chakli may be attributed to the fact that might have developed rancidity.

\section{Introduction}

Phoenix dactylifera L. commonly known as date or date palm is a monocotyledonous woody perennial plant which belongs to the Arecaceae family. It is also known as Khajur and due to its high nutritional value and long life it is also known as "Tree of Life" (Al Farsi and Lee, 2008). Phoenix dactylifera L. is presumably derived from a Phoenician name "Phoenix", which means date palm and "dactylifera" means 'date bearing', derived from a Greek word "daktulos" meaning a finger, illustrating the fruit from. 
Date harvesting states in India include Rajasthan, Gujarat, South Indian States of Tamil Nadu and Kerala. Production of dates in Rajasthan is 800 tonnes of date palm in 20152016. The major date production districts include Jaisalmer, Bikaner, Jodhpur, Barmer, Pali, Hanumangarh, Sri Ganganagar, Nagaur, Jalore, Jhunjhuunu, Sirohi and Churu (http://m.businesstoday.in/story/rajasthanproduces-800-tonnes-date-palms-from-firstharvest/1/236233.html).

Dates have also been shown to contain antioxidant and antimutagenic properties. Its pulp contains easily digestible sugars, dietary fibers and less protein and fat. They also contain vitamins like riboflavin, thiamine, biotin, folic and ascorbic acid that are essential for the body. The pulp is rich in iron, calcium, cobalt, copper, fluorine, magnesium, manganese, potassium, phosphorus, sodium, copper, sulfur, boron, selenium and zinc (Al Farsi and Lee, 2008; Ali Mohamed and Khamis, 2004. In folklore traditional medicine, the date powder is considered to be the best medicine for diabetic patients due to lower content of fructose because on drying the content of fructose gets reduced. Dates possess diverse medicinal uses including antihyperlipidemic, anticancerous, gastroprotective, hepatoprotective and nephroprotective activities and thereby serving as an important healthy food in the human diet (Baliga et al., 2011).

Dates are of explicit quality with great nutritional, organoleptic and economic importance and may help in providing food and nutritional security. It is also helpful in checking desertification; improve microclimate and economic upliftment of rural masses by generation of employment besides giving net monitory income to the framers. Due to its remarkable economic and nutritional value in addition to their aesthetic and environmental advantages dates are especially a delicious fruit. Dates are consumed in a variety of ways. They may be consumed as fresh $(30 \%-40 \%)$ or in the dried form $(60 \%-70 \%)$ at Rutab (semiripe) and Tamar (fully ripe) stages with little or no processing.

Medjhool dates are also known as the "King of dates". These dates are easily consumed by person of all age group because it is soft and nutritionally superior. It can also be consumed in the milk, with the milk and in the form of candies etc. When used in baking they provide superb taste to the final product. It is used as component in food preparations snacks, icecream, confectionaries, health foods etc. Processing of dates includes sorting, pitting, disinfestation of insects, washing, grading, heat treatment, adjusting moisture content, coating, pasteurization and packaging. Fermented products from date include alcohol, wine and organic acids. The availability of dates all over the country is high and they have tremendous nutritional and health benefits still their consumption especially by children and adolescent is low. Also the processing of dates into value added products is comparatively very less. Hence the present study is undertaken to develop value added products and to assess the shelf of the developed products of dates.

\section{Objectives of the study}

To develop value added products of date palm fruit.

To determine the shelf- life of the developed products.

\section{Materials and Methods}

\section{Locale of study}

The present study was conducted in the Department of Food Science and Nutrition, 
College of Home Science and laboratory of College of Dairy and Food Science Technology (CDFST), MPUAT, Udaipur.

\section{Procurement of sample}

Pretreated and dried dates of Medjhool variety as confirmed by the shopkeeper were procured from the local market. To ensure homogeneity of the sample they were selected according to their quality attributes such as uniform degree of maturity based on skin colour, size and shape. The other raw materials required for preparing value added products were procured in a single lot from the local market of Udaipur city.

Preparation and standardization of value added products

\section{Preparation}

In recent years, dependence on commercially available "Ready-to-eat" and "Ready-tocook" foods has increased in India. A large numbers of Indian dishes are now available and these foods are gaining popularity among Indian population. Convenience foods have given consumers a better choice because of good taste, ease of preparation, adequate nutrition, longer shelf life, ease of storage and attractive appearance with "just made" flavour and texture.

The locally available dried dates were used for developing four value added products ("Ready-to-eat" and "Ready-to-cook" products). Firstly dried dates powder was made. The procedure is as follows:

\section{Date cookies}

Cookies are baked, edible, and delicious and flour based food products which are liked by majority of all age groups. It is a ready-to-eat snack, possess several attractive features including wider consumption base, relatively long shelf life, more convenience and good eating quality.

\section{Dates Churan}

Churan is a digestive ball with sweet tangy taste. Churan is ready-to-eat product, possess several attractive features including wider consumption base, relatively long shelf life more convenience and good eating quality. Long shelf life of churan makes larger scale production and distribution possible.

\section{Dates Chakli}

Chakli is a deep fried savourvy snack. It is traditional food preparation and is widely consumed by local population as a snack. It is ready-to-eat snack, possess several attractive features including wider consumption base.

\section{Instant cake-premix}

The cake premix is a nutritious delicious and the flour based product which is liked by majority of all age groups. It is ready- to-cook snacks, possess several attractive features including wider consumption base, relatively long shelf life more convenience food and good eating quality. Long shelf life of instant cake premix makes larger scale production and distribution possible.

\section{Standardization of value added products}

The prepared dates powder was incorporated at different levels for preparation of the above mentioned value added products.

The date powder was incorporated at different levels that is for cookies, chakli and instant cake premix the dates powder was incorporated at three different levels that is 80:20, 70:30 and 60:40 and churan was prepared with 100 percent dates powder. The 
products were also be standardized for serving size and cooking time.

All the developed products were standardized in the lab for their sensory characteristics using 9 point Hedonic Rating Scale (Swaminathan, 1987) with a panel of thirty judges.

\section{Shelf life assessment of date fruit products}

The value added products developed by using dates powder is stored for a period of 3 months. The shelf life of the stored products was evaluated at 0, 30, 60 and 90 days for moisture content, organoleptic parameter and microbial growth (yeast count). For estimation of shelf life of the product total one hundred gram of sample was taken.

\section{Sensory evaluation}

Organoleptic or sensory evaluation refers to the evaluation of recipes by some organs. The acceptance or rejection is based largely on the stimulus of sense organs of an individual. All the recipes were evaluated for their sensory characteristics such as appearance, colour, flavour, taste, texture and overall acceptability by 30 selected members. (Swaminathan, 1987).

\section{Selection of panel members}

Dilution test described as subjective test useful in selection and training panel was used for selecting the panel. For this taste dilution of salts at levels 0, 20, 40, 60, and $80 \mathrm{mg}$ per 100 $\mathrm{ml}$ of water were used. All the dilutions were marked and arranged in random odder 30 members including staff and student of the college were asked to arrange the salt solutions in increasing odder of their salinity. A panel of 30 members who arrange the solutions in correct odder of salinity, willing and available during the study periods were selected.

\section{Moisture (NIN 2003)}

Moisture is the major component of food. The moisture content of any food is determined not only to analyze the chemical composition of food material on moisture free basis but also to assess the shelf life of the products.

\section{Method}

Ten gram sample was weighed in Petri dish. The weight of the sample along with the petri dish was taken at regular intervals until a constant weight was obtained. The moisture percentage was calculated using following formula:

Moisture $(\mathrm{g} / 100 \mathrm{~g})=\frac{\text { Initial weight }(\mathrm{g})-\text { Final weight }(\mathrm{g})}{\text { Weight of the sample }(\mathrm{g})} \times 100$

\section{Microbial growth (yeast count)}

Micro-organisms are closely related to the health and welfare of human being. In the present study, dates powdered products prepared from date powder will be examined for the presence of micro-organisms like yeast and mould using standard procedure (ISI.,1981) at zero to three months of storage period. Details are as follows:

\section{Composition of agar}

The composition of different types of agar used for the direction of microbial growth in dates powder products are presented below.

\section{Yeast and mould count}

The mould count was carried out using potato dextrose agar (BIS 5403:1999). Initial product sample homogenates were prepared in sterile diluents in the ratio of $1: 10.1 \mathrm{ml}$ of each homogenate was then aseptically diluted in series up to a dilution of 10-3. The diluents were poured in plates in duplicates. Incubation was done at $25^{\circ} \mathrm{c}$ for $72 \mathrm{hrs}$. Yeast and mould 
counts were expressed as Colony Forming Units per gram $(\mathrm{CFU} / \mathrm{g})$.

\section{Results and Discussion}

Food product quality maintenance and management are critical factors that regulate its acceptance and also determine the shelf life of the product. Any little change in the external or internal factors can cause quality deterioration, which can be time specific too. Shelf life of the food products is, therefore, specified to give information about the time period in which the product is to be consumed. To attain knowledge of a food's expected shelf life, one must understand the microbial, enzymatic and reactions that simultaneously take place in any given food, identify the mechanisms responsible for spoilage or loss of desirable characteristics such as aroma, odour or nutrient and implement scientific models for estimating the period for which it will retain an acceptable level of eating quality from a safety and organoleptic perspective. The principle mechanisms involved in the deterioration of processed foods are

Microbial spoilage sometimes accompanied by pathogens development.

Chemical and enzymatic activity causing lipid breakdown, colour, aroma and textural change.

Moisture content of the product leading to a change in the water activity.

Changes occurring due to the inefficient packaging system.

In this paper, data regarding the sensory and microbial profile of the standardized products during the storage period has been delineated. Products were checked for its keeping quality for three months. Hundred gram products were prepared and packed in high density polythene pouches and stored at room temperature for the period of three months. During this period the products were analyzed for moisture content, sensory evaluation and microbial examination (yeast count) at 0,30 , 60 and 90 days of storage.

\section{Effect of storage on sensory attributes of the products}

The organoleptic acceptability of a food product is a composite effect of different sensory attributes viz., colour, appearance, texture, flavour, taste and overall acceptability. The products were subjected to sensory analysis by a selected group of panelist for their individual sensory attributes, at monthly intervals for a period of three months. The sensory scores assigned by the panel members at nine-point Hedonic Rating Scale during entire storage duration were statistically analyzed using one way analysis of variance. The results for sensory evaluation of products have been presented in Tables 2-5. The results are discussed here under:

\section{Dates cookies}

Sensory evaluation of date's cookies between storage period (0-3 months) is presented in Table 1 . There was no significant difference observed between storage periods in sensory characteristics of date's cookies. The sensory scores for all attributes indicated an acceptability level of 7- 8 (liked moderately to liked very much) up to $2^{\text {nd }}$ month. In $3^{\text {rd }}$ month scores was also at the range of 7-8 which indicates an acceptability level of "liked moderately" to "like very much".

\section{Dates chakli}

Sensory evaluation of dates chakli between storage period (0-3 months) is presented in Table 2 given below. 
Table.1 Potato Dextrose Agar (PDA)

\begin{tabular}{|l|c|}
\hline \multicolumn{1}{|c|}{ Ingredients } & Amount g/lit \\
\hline Infusion from potatoes & 200 \\
\hline Dextrose & 20 \\
\hline Agar & 20 \\
\hline Distilled water & 1 lit \\
\hline
\end{tabular}

Table.2 Sensory evaluation of date's cookies by storage period

\begin{tabular}{|c|c|c|c|c|c|c|}
\hline Day & Appearance & Colour & Taste & Flavour & Texture & $\begin{array}{c}\text { Overall } \\
\text { Acceptability }\end{array}$ \\
\hline $\mathbf{0}$ & $8.27 \pm 0.83$ & $7.93 \pm 0.78$ & $8.00 \pm 0.83$ & $7.90 \pm 0.84$ & $8.10 \pm 0.80$ & $7.67 \pm 0.80$ \\
\hline $\mathbf{3 0}$ & $8.17 \pm 0.87$ & $8.07 \pm 0.87$ & $8.27 \pm 0.78$ & $7.97 \pm 0.85$ & $8.17 \pm 0.79$ & $8.07 \pm 0.69$ \\
\hline $\mathbf{6 0}$ & $7.87 \pm 0.82$ & $7.97 \pm 0.81$ & $8.03 \pm 0.81$ & $8.03 \pm 0.81$ & $7.87 \pm 0.78$ & $8.00 \pm 0.83$ \\
\hline $\mathbf{9 0}$ & $7.77 \pm 0.73$ & $7.93 \pm 0.87$ & $7.97 \pm 0.85$ & $7.93 \pm 0.83$ & $8.10 \pm 0.80$ & $7.87 \pm 0.78$ \\
\hline GM & $\mathbf{8 . 0 2}$ & $\mathbf{7 . 9 8}$ & $\mathbf{8 . 0 7}$ & $\mathbf{7 . 9 6}$ & $\mathbf{8 . 0 6}$ & $\mathbf{7 . 9 0}$ \\
\hline SE & $\mathbf{0 . 2 1}$ & $\mathbf{0 . 2 2}$ & $\mathbf{0 . 2 1}$ & $\mathbf{0 . 2 2}$ & $\mathbf{0 . 2 0}$ & $\mathbf{0 . 2 0}$ \\
\hline CD $(\mathbf{5 \%})$ & $\mathbf{0 . 4 8}$ & $\mathbf{0 . 4 9}$ & $\mathbf{0 . 4 8}$ & $\mathbf{0 . 4 9}$ & $\mathbf{0 . 4 7}$ & $\mathbf{0 . 4 6}$ \\
\hline CD $(\mathbf{1 \%})$ & $\mathbf{0 . 6 0}$ & $\mathbf{0 . 6 2}$ & $\mathbf{0 . 6 1}$ & $\mathbf{0 . 6 2}$ & $\mathbf{0 . 5 9}$ & $\mathbf{0 . 5 7}$ \\
\hline CV & $\mathbf{2 . 7 1 \%}$ & $\mathbf{2 . 7 8 \%}$ & $\mathbf{2 . 7 3 \%}$ & $\mathbf{2 . 7 8 \%}$ & $\mathbf{2 . 6 4 \%}$ & $\mathbf{2 . 5 9 \%}$ \\
\hline & & & & & & \\
\hline
\end{tabular}

Table.3 Sensory evaluation of dates chakli by storage period

\begin{tabular}{|c|c|c|c|c|c|c|}
\hline Day & Appearance & Colour & Taste & Flavour & Texture & $\begin{array}{c}\text { Overall } \\
\text { Acceptability }\end{array}$ \\
\hline $\mathbf{0}$ & $8.40 \pm 0.50$ & $8.37 \pm 0.49$ & $8.60 \pm 0.50$ & $8.43 \pm 0.50$ & $8.37 \pm 0.49$ & $8.57 \pm 0.50$ \\
\hline $\mathbf{3 0}$ & $7.90 \pm 0.76$ & $8.07 \pm 0.74$ & $7.97 \pm 0.81$ & $8.17 \pm 0.83$ & $8.00 \pm 0.74$ & $8.03 \pm 0.81$ \\
\hline $\mathbf{6 0}$ & $7.60 \pm 0.93$ & $7.50 \pm 1.17$ & $7.40 \pm 0.97$ & $7.47 \pm 1.36$ & $7.47 \pm 1.14$ & $7.47 \pm 1.07$ \\
\hline $\mathbf{9 0}$ & $7.60 \pm 1.25$ & $7.07 \pm 1.41$ & $6.73 \pm 1.48$ & $7.10 \pm 1.47$ & $6.97 \pm 1.50$ & $6.93 \pm 1.36$ \\
\hline GM & $\mathbf{7 . 8 8}$ & $\mathbf{7 . 7 5}$ & $\mathbf{7 . 6 8}$ & $\mathbf{7 . 7 9}$ & $\mathbf{7 . 7 0}$ & $\mathbf{7 . 7 5}$ \\
\hline SE & $\mathbf{0 . 2 3}$ & $\mathbf{0 . 2 6}$ & $\mathbf{0 . 2 6}$ & $\mathbf{0 . 2 9}$ & $\mathbf{0 . 2 7}$ & $\mathbf{0 . 2 6}$ \\
\hline CD (5\%) & $\mathbf{0 . 5 3}$ & $\mathbf{0 . 6 0}$ & $\mathbf{0 . 5 9}$ & $\mathbf{0 . 6 5}$ & $\mathbf{0 . 6 1}$ & $\mathbf{0 . 5 8}$ \\
\hline CD $(\mathbf{1 \%})$ & $\mathbf{0 . 6 7} * *$ & $\mathbf{0 . 7 5 * *}$ & $\mathbf{0 . 7 4} * *$ & $\mathbf{0 . 8 2} * *$ & $\mathbf{0 . 7 7} * *$ & $\mathbf{0 . 7 3} * *$ \\
\hline CV & $\mathbf{3 . 0 1 \%}$ & $\mathbf{3 . 3 9 \%}$ & $\mathbf{3 . 3 5 \%}$ & $\mathbf{3 . 7 1 \%}$ & $\mathbf{3 . 4 7 \%}$ & $\mathbf{3 . 3 0 \%}$ \\
\hline
\end{tabular}

**Significant at $1 \%$ level of significance

Table.4 Sensory evaluation of Instant cake premix by storage period

\begin{tabular}{|c|c|c|c|c|c|c|}
\hline Day & Appearance & Colour & Taste & Flavour & Texture & $\begin{array}{c}\text { Overall } \\
\text { Acceptability }\end{array}$ \\
\hline $\mathbf{0}$ & $7.50 \pm 1.04$ & $7.67 \pm 0.99$ & $7.63 \pm 1.22$ & $7.57 \pm 1.07$ & $7.27 \pm 1.08$ & $7.30 \pm 1.15$ \\
\hline $\mathbf{3 0}$ & $8.03 \pm 1.00$ & $7.50 \pm 1.04$ & $7.37 \pm 1.13$ & $7.40 \pm 1.22$ & $7.40 \pm 1.22$ & $7.47 \pm 1.11$ \\
\hline $\mathbf{6 0}$ & $7.33 \pm 1.12$ & $7.70 \pm 1.02$ & $7.70 \pm 1.26$ & $7.63 \pm 1.16$ & $7.77 \pm 0.94$ & $7.33 \pm 1.12$ \\
\hline $\mathbf{9 0}$ & $7.23 \pm 1.30$ & $7.63 \pm 1.03$ & $7.17 \pm 1.15$ & $7.20 \pm 1.19$ & $7.70 \pm 0.95$ & $7.33 \pm 0.99$ \\
\hline GM & $\mathbf{7 . 5 3}$ & $\mathbf{7 . 6 3}$ & $\mathbf{7 . 4 7}$ & $\mathbf{7 . 4 5}$ & $\mathbf{7 . 5 3}$ & $\mathbf{7 . 3 6}$ \\
\hline SE & $\mathbf{0 . 2 9}$ & $\mathbf{0 . 2 6}$ & $\mathbf{0 . 3 1}$ & $\mathbf{0 . 3 0}$ & $\mathbf{0 . 2 7}$ & $\mathbf{0 . 2 8}$ \\
\hline CD $(\mathbf{5 \%})$ & $\mathbf{0 . 6 6}$ & $\mathbf{0 . 6 0}$ & $\mathbf{0 . 7 0}$ & $\mathbf{0 . 6 8}$ & $\mathbf{0 . 6 2}$ & $\mathbf{0 . 6 4}$ \\
\hline CD $(\mathbf{1 \%})$ & $\mathbf{0 . 8 3}$ & $\mathbf{0 . 7 6}$ & $\mathbf{0 . 8 8}$ & $\mathbf{0 . 8 6}$ & $\mathbf{0 . 7 8}$ & $\mathbf{0 . 8 1}$ \\
\hline CV & $\mathbf{3 . 7 5 \%}$ & $\mathbf{3 . 4 1 \%}$ & $\mathbf{3 . 9 7 \%}$ & $\mathbf{3 . 8 7 \%}$ & $\mathbf{3 . 5 1 \%}$ & $\mathbf{3 . 6 5 \%}$ \\
\hline & & & & & & \\
\hline
\end{tabular}


Table.5 Sensory evaluation of date's churan by storage period

\begin{tabular}{|c|c|c|c|c|c|c|}
\hline Day & Appearance & Colour & Taste & Flavour & Texture & $\begin{array}{c}\text { Overall } \\
\text { Acceptability }\end{array}$ \\
\hline 0 & $8.00 \pm 0.83$ & $8.00 \pm 0.87$ & $8.10 \pm 0.80$ & $8.23 \pm 0.90$ & $7.93 \pm 0.87$ & $7.70 \pm 0.88$ \\
\hline 30 & $7.83 \pm 0.83$ & $8.07 \pm 0.87$ & $7.93 \pm 0.74$ & $7.87 \pm 0.78$ & $7.83 \pm 0.87$ & $7.77 \pm 0.90$ \\
\hline 60 & $8.10 \pm 0.80$ & $7.90 \pm 0.76$ & $8.10 \pm 0.84$ & $7.87 \pm 0.73$ & $7.90 \pm 0.84$ & $7.60 \pm 0.72$ \\
\hline 90 & $8.03 \pm 0.81$ & $7.70 \pm 0.75$ & $8.20 \pm 0.76$ & $8.20 \pm 0.85$ & $8.13 \pm 0.78$ & $7.97 \pm 0.89$ \\
\hline GM & 7.99 & 7.92 & 8.08 & 8.04 & 7.95 & 7.76 \\
\hline SE & 0.21 & 0.21 & 0.20 & 0.21 & 0.22 & 0.22 \\
\hline $\begin{array}{c}\text { CD } \\
(5 \%)\end{array}$ & 0.48 & 0.48 & 0.46 & 0.48 & 0.49 & 0.50 \\
\hline $\begin{array}{c}\text { CD } \\
(1 \%)\end{array}$ & 0.61 & 0.60 & 0.58 & 0.60 & 0.62 & 0.63 \\
\hline $\mathrm{CV}$ & $2.73 \%$ & $2.71 \%$ & $2.63 \%$ & $2.72 \%$ & $2.81 \%$ & $2.83 \%$ \\
\hline
\end{tabular}

Table.6 Effect of storage (days) on yeast and mold count ( $\mathrm{cfu} / \mathrm{g}$ ) of dates products

\begin{tabular}{|c|c|c|c|c|}
\hline Day & Dates Cookies (B) & Dates Chakli (D) & $\begin{array}{c}\text { Instant Cake } \\
\text { Premix (C) }\end{array}$ & $\begin{array}{c}\text { Dates Churan } \\
\text { (A) }\end{array}$ \\
\hline $\mathbf{0}$ & NIL & NIL & NIL & NIL \\
\hline $\mathbf{3 0}$ & $0.11 \pm 0.01$ & $0.13 \pm 0.03$ & $0.12 \pm 0.01$ & $0.11 \pm 0.01$ \\
\hline $\mathbf{6 0}$ & $0.11 \pm 0.01$ & $0.23 \pm 0.06$ & $0.12 \pm 0.01$ & $0.12 \pm 0.01$ \\
\hline $\mathbf{9 0}$ & $0.12 \pm 0.02$ & $0.54 \pm 0.13$ & $0.11 \pm 0.01$ & $0.11 \pm 0.01$ \\
\hline GM & $\mathbf{0 . 0 9}$ & $\mathbf{0 . 2 3}$ & $\mathbf{0 . 0 9}$ & $\mathbf{0 . 0 9}$ \\
\hline SE & $\mathbf{0 . 0 0 7}$ & $\mathbf{0 . 0 5 8}$ & $\mathbf{0 . 0 0 4}$ & $\mathbf{0 . 0 0 7}$ \\
\hline CD 5\% & $\mathbf{0 . 0 2}$ & $\mathbf{0 . 1 6}$ & $\mathbf{0 . 0 1}$ & $\mathbf{0 . 0 2}$ \\
\hline CD 1\% & $\mathbf{0 . 0 3}$ & $\mathbf{0 . 2 2} * *$ & $\mathbf{0 . 0 2}$ & $\mathbf{0 . 0 3}$ \\
\hline CV & $\mathbf{0 . 0 3 \%}$ & $\mathbf{0 . 1 2 \%}$ & $\mathbf{0 . 0 1 \%}$ & $\mathbf{0 . 0 2 \%}$ \\
\hline
\end{tabular}

**Significant at $1 \%$ level of significance

Table.7 Effect of storage (days) on Moisture (g) of dates products

\begin{tabular}{|c|c|c|c|c|}
\hline Day & Cookies (B) & Chakli (D) & Instant Cake Premix (C) & Churan (A) \\
\hline $\mathbf{0}$ & $0.64 \pm 0.01$ & $1.41 \pm 0.08$ & $1.16 \pm 0.10$ & $0.54 \pm 0.03$ \\
\hline $\mathbf{3 0}$ & $0.63 \pm 0.00$ & $1.68 \pm 0.06$ & $1.16 \pm 0.08$ & $0.56 \pm 0.02$ \\
\hline $\mathbf{6 0}$ & $1.33 \pm 0.05$ & $2.15 \pm 0.02$ & $2.15 \pm 0.13$ & $1.05 \pm 0.06$ \\
\hline $\mathbf{9 0}$ & $2.56 \pm 0.02$ & $4.43 \pm 0.04$ & $4.12 \pm 0.09$ & $2.05 \pm 0.05$ \\
\hline GM & $\mathbf{1 . 2 9}$ & $\mathbf{2 . 4 2}$ & $\mathbf{2 . 1 5}$ & $\mathbf{1 . 0 5}$ \\
\hline SE & $\mathbf{0 . 0 2}$ & $\mathbf{0 . 0 5}$ & $\mathbf{0 . 0 8}$ & $\mathbf{0 . 0 3}$ \\
\hline CD $(\mathbf{5 \%})$ & $\mathbf{0 . 0 6}$ & $\mathbf{0 . 1 2}$ & $\mathbf{0 . 2 3}$ & $\mathbf{0 . 0 9}$ \\
\hline CD $(\mathbf{1 \%})$ & $\mathbf{0 . 0 8} * *$ & $\mathbf{0 . 1 7} * *$ & $\mathbf{0 . 3 2} * *$ & $\mathbf{0 . 1 3} * *$ \\
\hline CV & $\mathbf{0 . 0 8 \%}$ & $\mathbf{0 . 0 9 \%}$ & $\mathbf{0 . 2 3 \%}$ & $\mathbf{0 . 0 9 \%}$ \\
\hline
\end{tabular}

**Significant at $1 \%$ level of significance 
Fig.1 Value added products of dates

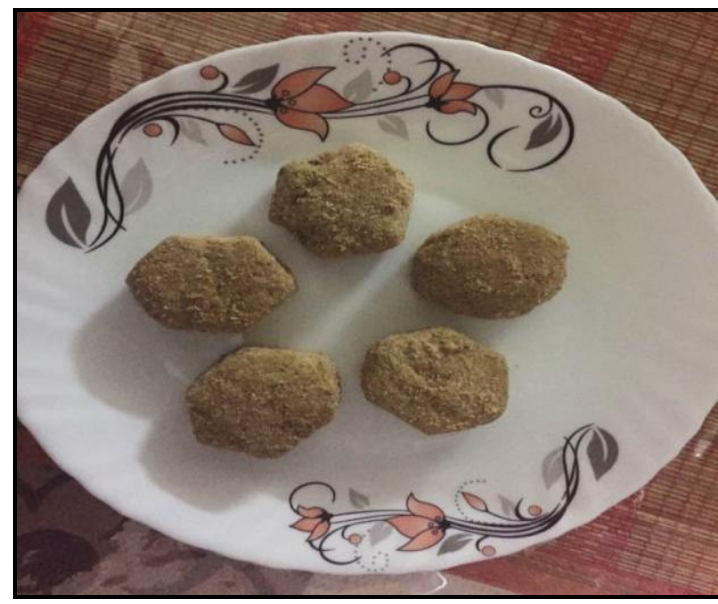

B3 (60:40) Dates Cookies

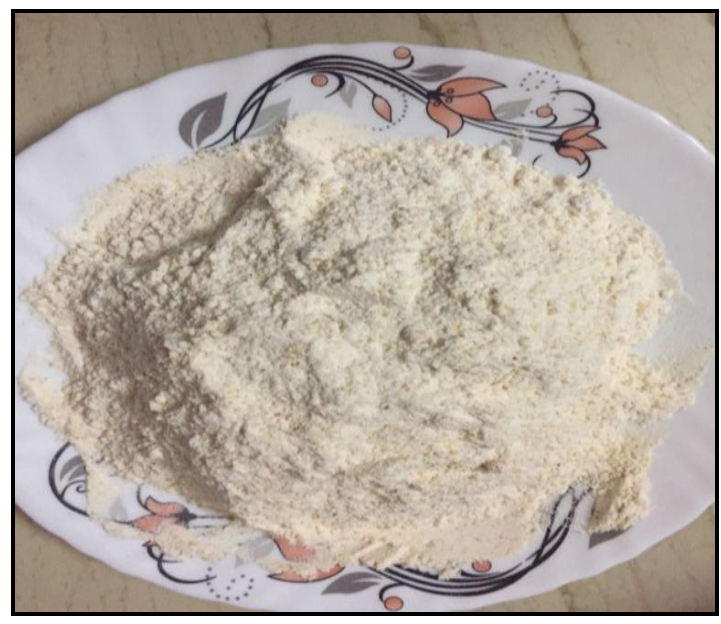

C3 (60:40) Instant cake premix

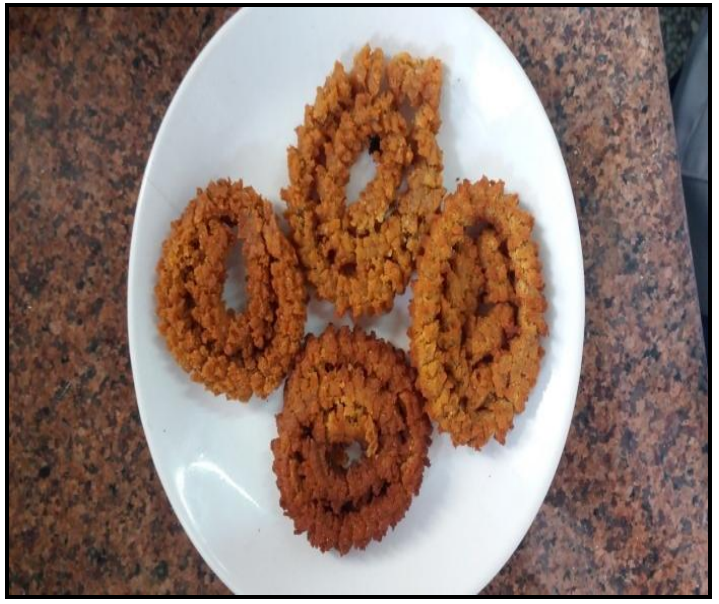

D3 (60:40) Dates Chakli

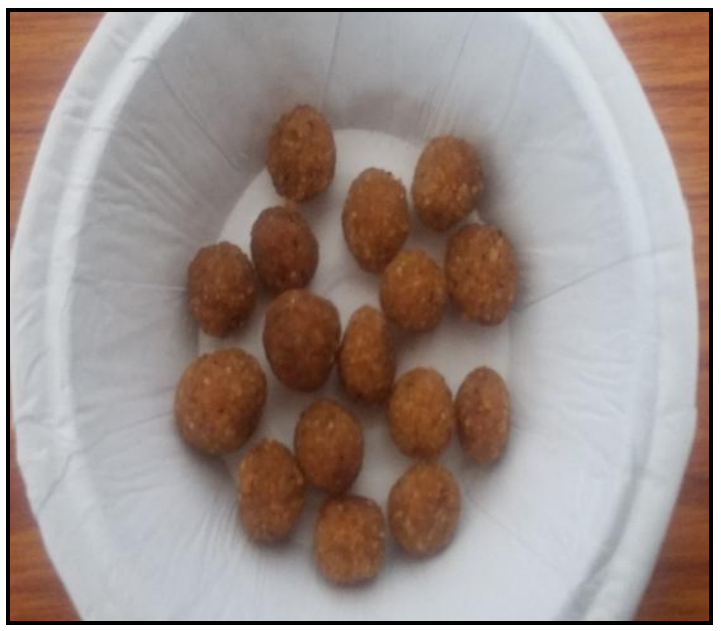

(100\%) Khatta Meetha Churan

Fig.2 Microbial growth of dates products

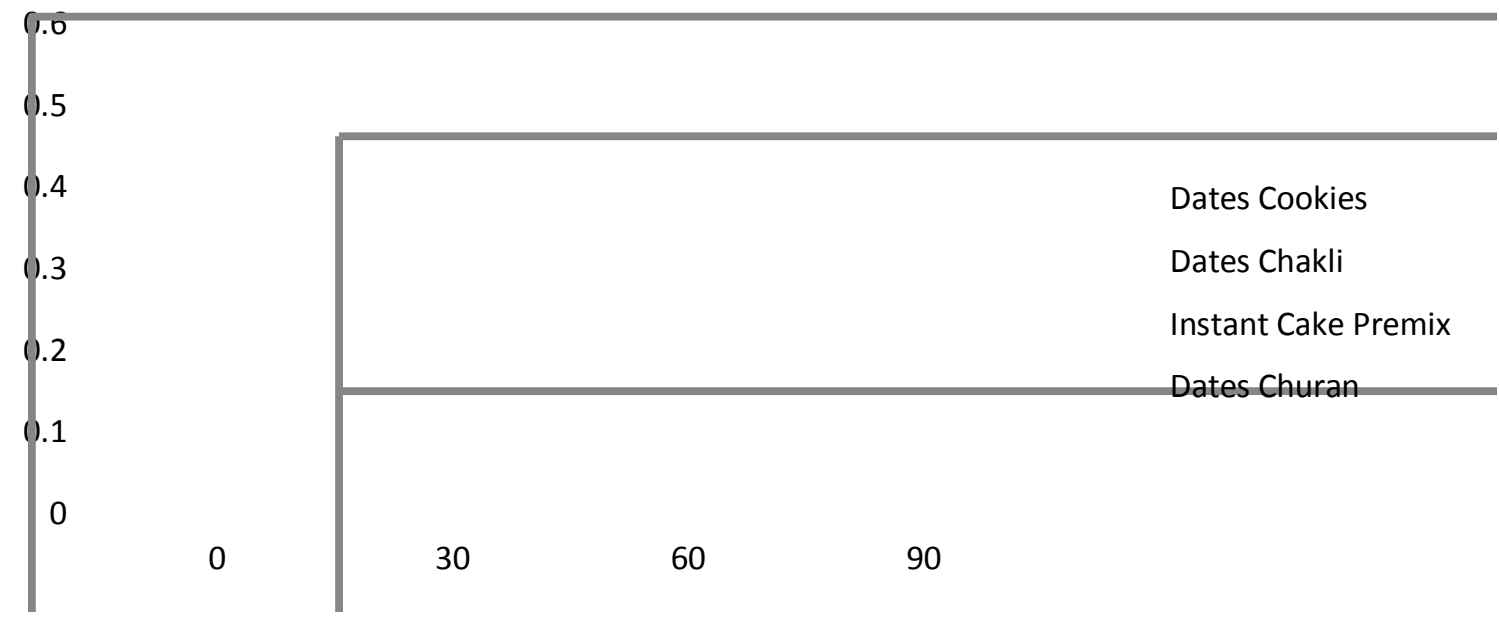


Fig.3 Moisture per cent content of dates products

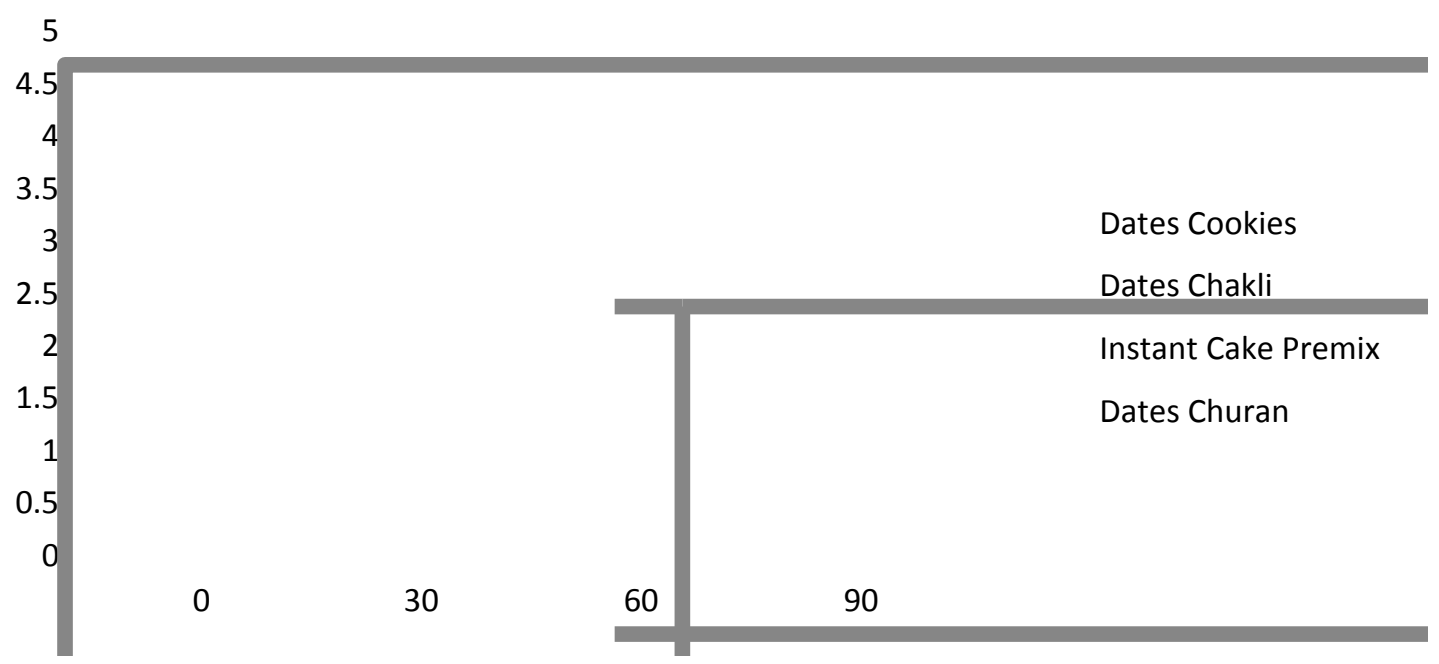

There was no significant difference was observed between storage periods in sensory characteristics of dates chakli. Although a slight decrease in colour, appearance, texture, flavour was observed in the period of $3^{\text {rd }}$ month but the score indicates "Like moderately".

In the second month dates chakli scored as liked very much for appearance to texture and overall acceptability revealed that for period of one month dates chakli was found highly acceptable and after second month a slight degradation was observed in sensory scores but it was acceptable for consumption. Highly significant difference in the sensory scores in dates chakli was found $(p>0.001)$ after the third month of storage.

\section{Instant cake premix}

Instant cake premix is a ready to cook food. Sensory evaluation of instant cake premix during storage period is presented in Table 3. There was no significant difference observed in sensory attributes like colour, appearance, texture, aroma, taste and overall acceptability during 3 month of storage period.

\section{Dates Churan}

Table 4 represents the sensory evaluation of dates churan between storage period (0-3 months). The observations revealed that there was no significant difference in appearance and texture, colour, aroma, taste, and overall acceptability on storage, but the sensory scores for all attributes indicated an acceptability level of 7-8 (liked moderately to liked very much) up to $2^{\text {nd }}$ month. In $3^{\text {rd }}$ month also scores were in the range of 7-8 which indicates an acceptability level of liked moderately to like very much.

\section{Microbial examination}

In recent years, the increasing consumer awareness has emphasized the need for microbiologically safe food. Since the human food supply consists basically of plant and animal products. It is understandable that the food supply may contain microorganisms in interaction with the foods. When the microorganism involved is pathogenic, their association with the food is critical from a public health point of view. Serious health hazards due to the presence of pathogenic 
microbes in food can lead to food poisoning outbreaks (Frazier and Westhoff, 2001).

Microbial load is another determinant indicative of quality of any food product. Every step in handling and preparation of food may become a potential source of contamination.

Microorganisms in a healthy growing state may contain in excess of 80 per cent water. They get this water from food in which they grow. If the water is removed from the food, water will also be removed from the bacteria cells and multiplication will stop. Bacteria and yeasts generally require more moisture than molds, so molds often will be found growing on semi-dry foods where bacteria and yeasts find conditions unfavorable (Potter and Hotchkiss, 2007).

Microbial load of the dates products during their storage has been presented in the Table 5 and figure 1.

Microbial examination revealed that the yeast and mould counts in the dates churan, dates cookie, instant cake premix and dates chakli were nil prior to their storage (0 day). After that, they are packed in the high density polythene had no significant changes (dates churan, dates cookies and instant cake premix) throughout the storage period but significantly high difference was found in dates chakli during the storage period ( $>>0.001)$.

\section{Moisture analysis}

Moisture being one of the important determinants of shelf life of dried product was monitored at regular intervals during storage period of three months. The mean values for moisture content from the three replicates of the products stored in HDPE are presented in Table 6 and figure 2 given below.
Table 6 shows that the average mean values of moisture content of the products packed in HDPE was dates churan (1.05\%), dates cookies (1.29\%), instant cake premix (2.15\%) and dates chakli $(2.42 \%)$ on 0,30 , 60 and 90 days respectively. The table further depicts significant increase $(\mathrm{p} \leq 0.001)$ at $2^{\text {nd }}$ and $3^{\text {rd }}$ month of storage period in the ordinary heat sealed packed products (Fig. 3).

Based on the results of organoleptic, nutritional and shelf life, it can be concluded that the four dates products that are made in the study are nutritionally sound and can be consumed by every age group. The shelf life examination revealed that the date's products (dates cookies, dates churan and Instant cake premix) are safe for consumption up to three months of storage at ambient temperature but dates chakli get spoiled after 2 months.

\section{References}

Al Farsi, M. A. and Lee, C. Y. 2008. Nutritional and functional properties of dates: a review. Food Science and Nutrition, 48: 877-887.

Ali Mohamed, A. Y. and Khamis, A. S. 2004. Mineral ion content of the seeds of six cultivars of Bahraini date palm (Phoenix dactylifera). Journal of Agricultural and Food Chemistry, 52: 6522-6525.

Al-Shahib, W. and Marshall, R. J. 2003. The fruit of the date palm: Its possible use as the best food for the future. International Journal of Food Science and Nutrition, 54: 247-259.

Baliga, M.S., Baliga, B.R., Kandathil, S.M., Bhat, H.P. and Vayalil, P.K. 2011. A Review of the chemistry and pharmacology of the Date fruits (Phoenix dactylifera L.). Food Research International, 44:1812-1822. 
Frazier, W.C. and Westhoff, D.C. 2001. Food Microbiology. Tata McGraw-Hill, New Delhi.

Khan, M., Sarwar, A., Wahab, M., and Haleem, R. 2008. Physio-chemical characterization of date varieties using multivariate analysis. Journal of Food Agriculture, 88: 1051-1059.

Potter, N.N. and Hotchkiss, J. H. 2007. Food Science. CBS Publishers and distributors, New Delhi. (5 ${ }^{\text {th }}$ ed.).
Rajasthan produces 800 tonnes date palms from first harvest. Dated 14-05-2017 Retrieved from http://m.businesstoday. in/story/rajasthan-produces-800-tonnesdate-palms-from-firstharvest/1/236233.html.

Swaminathan, M. 1987. Sensory methods of analysis of foods. Food Science and Experimental Foods. Ganesh 293p.

\section{How to cite this article:}

Nikita Wadhawan and Rythm Bansal. 2018. A Study on Microbial Characteristics of Food Products Developed from Dates (Phoenix dactylifera L.). Int.J.Curr.Microbiol.App.Sci. 7(08): 441-451. doi: https://doi.org/10.20546/ijcmas.2018.708.050 